\title{
LEITURA FRUIÇÃO NA EDUCAÇÃO INFANTIL: O PAPEL DO PROFESSOR MEDIADOR NA FORMAÇÃO DE LEITORES
}

\author{
Samuel Mendonça ${ }^{1}$ \\ Hellen Cristina Machado ${ }^{2}$ \\ Maria Silvia Pinto De Moura Librandi da Rocha ${ }^{3}$
}

\begin{abstract}
Resumo: O presente artigo, de natureza bibliográfica, busca compreender as possíveis interferências da prática pedagógica do professor de Educação Infantil, pautadas na perspectiva histórico-cultural de Lev Semenovitch Vigotski. Considerando a grande representatividade que a escrita alfabética tem em nossa sociedade grafocêntrica, procura-se pensar meios em que o professor pode atuar na zona de desenvolvimento proximal de seus alunos. Com isso, almeja-se maturar o conhecimento prévio que os alunos de Educação Infantil têm sobre o livro e a leitura por meio da leitura fruição, aqui entendida com uma prática desprovida de obtenção de resultados, ou seja, o ler por gosto de ler, para a partir dessa prática cotidiana, os alunos de Educação Infantil se sentirem próximos e interessados pela leitura e procurem a mesma por seus próprios gostos.
\end{abstract}

Palavras-chave: Leitura fruição; Mediação pedagógica; Perspectiva histórico-cultural.

\section{READING FOR PLEASURE IN KINDERGARTEN: THE ROLE OF THE MEDIATOR TEACHER IN THE FORMING READERS}

\begin{abstract}
This article of bibliographic approach seeks to understand the possible interference of the pedagogical practice of kindergarten teachers, guided by the historical-cultural perspective of Lev Vygotsky Semenovitch. Considering the major importance that alphabetic writing has in our graphocentric society, we try to think of ways in which teachers can act in the zone of proximal development of their students. Thus, we aim to improve the prior knowledge that young children have on books and reading by reading for pleasure, regardless of getting results. With this daily practice it is expected to enhance children's interest on reading and help them to start doing it based on their own tastes.
\end{abstract}

Keywords: Reading for pleasure; Pedagogical mediation; Cultural historical perspective.

\footnotetext{
${ }^{1}$ Doutor em Filosofia da Educação pela Unicamp. Professor e Coordenador do Programa de Pós-Graduação em Educação da Pontifícia Universidade Católica de Campinas. Pesquisador PQ 2 CNPq. Email: samuelms@gmail.com

${ }^{2}$ Mestranda em Educação pela PUC Campinas. Pedagoga e professora de Educação Infantil. Membro do grupo de pesquisa Formação e Trabalho Docente (CNPq/PUC Campinas). Email: hellenc-m@,hotmail.com

${ }^{3}$ Doutora em Educação pela Unicamp. Professora do Programa de Pós-Graduação em Educação da Pontifícia Universidade Católica de Campinas. Líder do grupo de pesquisa Formação e Trabalho Docente (CNPq/PUC Campinas). E-mail: silrocha@uol.com.br
} 


\section{INTRODUÇÃO}

Se há algo que faz a diferença na vida escolar de uma criança, por certo, é o desenvolvimento da habilidade de leitura. A leitura instrumental, isto é, a capacidade de compreender signos já denota avanço significativo em relação ao que se buscar compreender, dado que ao se instrumentalizar com o alfabeto, a criança estará apta a descortinar o mundo. A leitura quando demandada pelo próprio estudante não tem comparação em relação à leitura obrigatória, isto é, quando o estudante deseja a leitura por seus propósitos, pode-se afirmar que a leitura será efetiva, por prazer, por deleite, leitura fruição. A aprendizagem será significativa e o conhecimento será aprendido.

Este texto tem como objeto a leitura fruição como potência para o despertar dos interesses dos alunos de Educação Infantil. A motivação desta pesquisa está relacionada com experiência em sala de aula, no contexto de estágio supervisionado, da mesma forma que observações realizadas em diferentes instituições escolares foram fundamentais para que se pudesse constatar que é preciso pensar alternativas para o desenvolvimento da leitura como deleite. Se o desenvolvimento de um projeto pedagógico reivindica a aplicação de um currículo, a leitura é habilidade prevista para as crianças da Educação Infantil, no entanto, para além da leitura, é preciso compreender o que motiva e efetiva o interesse pela leitura fruição por parte dos estudantes.

A questão que inquieta na prática de leitura é o que faz as crianças gostarem desse momento, seja este em casa com os pais, seja na biblioteca ou em sala de aula. A partir disso, pensar em como a prática da professora em sala pode despertar o conhecimento e interesse da criança pela leitura. Previamente pensou-se em uma resposta à questão: deve ser o modo com que o educador ${ }^{4}$ lida com a leitura. Se for um cantinho da sala com livros expostos, assim como outros cantos que possuem brinquedos, e se não há na sala o costume de se ler um livro, dificilmente a criança entenderá qual sua relação com aquele objeto. Em contrapartida, se a educador incentiva momentos de leitura com ele em roda ou entre eles individualmente, se levam livros para casa, e essa prática faz parte do cotidiano dos alunos, logo perceberão os cuidados que devem ter com os livros, quais as características que os compõem, e que as imagens nos contam histórias tanto quanto as palavras.

\footnotetext{
${ }^{4}$ Existem pesquisas recentes tratando da questão da profissionalização de educadores, fazendo uma distinção do termo professor e educador. Um exemplo é o trabalho de Heloísa Helena Oliveira de Azevedo e Taciana Saciloto Real Cordão (2013). Porém, neste presente trabalho, não há a preocupação de tratar desta distinção.
} 
Para confirmar se a resposta prévia dada à questão tem fundamento, e se a intervenção do educador em sala modifica o contato de seus alunos com o objeto livro e a leitura, une-se à leitura fruição a perspectiva histórico-cultural de Vigotski. A perspectiva histórico-cultural diz respeito à aprendizagem da criança impulsionar o desenvolvimento, e que esta ocorre por meio de intervenções de adultos e crianças mais experientes, que instigam o nível de desenvolvimento proximal de uma criança, ou seja, o desenvolvimento em fase de maturação. Sendo assim, Smolka (2009, p. 8) argumenta que para Vigotski "O desenvolvimento da criança encontra-se, assim, intrinsecamente relacionado à apropriação da cultura”.

O artigo está organizado, do ponto de vista formal, em três momentos, a saber: (i) Leitura fruição na perspectiva histórico-cultural, em que se pretende compreender a epistemologia da psicologia histórico-cultural de Vigotski, levando em conta a zona de desenvolvimento proximal que o teórico constrói em seus estudos, para a intervenção do educador em sala de aula para despertar o interesse dos alunos da Educação Infantil pela leitura e o objeto livro; (ii) Leitura fruição - letramento literário, em que considera as intervenções pedagógicas possíveis ao professor de Educação Infantil na leitura fruição diária, intencionando o despertar do interesse dos alunos pelo gosto de ler, e fazendo-lhes relacionarse com o objeto livro de modo a conhecer as características literárias dele; (iii) A práxis educativa na perspectiva histórico-cultural, em que sistematiza e discute a respeito da mediação pedagógica para a formação do sujeito e as possíveis intervenções do educador em sala à luz da psicologia histórico-cultural na prática de leitura fruição.

\section{LEITURA FRUIÇÃO NA PERSPECTIVA HISTÓRICO-CULTURAL}

Em princípio, necessário se faz contextualizar a expressão leitura fruição, que ainda causa certo estranhamento sobre seu significado no ambiente acadêmico educacional. Ao consultarmos o Dicionário Aurélio (2001, p. 422) leitura se define como o "1. Ato, arte ou hábito de ler. [...] 3. Tec. Operação de percorrer, em um meio físico, sequências de marcas codificadas que representam informações registradas, e reconvertê-las à forma anterior (como imagens, sons, dados para processamento)"; fruir nada mais é do que "1. Estar na posse de; possuir. [...] 3. Desfrutar. § fru:i•ção" (1999, p. 335).

Logo, a leitura fruição em sala de aula na Educação Infantil é o momento em que o educador da turma se senta com seus alunos em roda e realiza a leitura de um livro literário infantil, trazendo às crianças o universo da leitura: a prática e gosto pelo ato de ler e ouvir 
histórias. Assim, do ponto de vista etimológico, leitura fruição é estar na posse e desfrutar de uma leitura com gozo.

A partir desta apresentação do termo, ponto central deste trabalho de pesquisa, une-se a este a perspectiva histórico-cultural (ou sociointeracionista) de Lev Semenovitch Vigotski ${ }^{5}$ que, decorrente da teoria marxista do materialismo histórico dialético, elaborou sua teoria que muito é usada na área da Psicologia e Pedagogia, pois acredita, na interpretação de Colaço (et al, 2007) que "[...] a aprendizagem gera desenvolvimento, ou seja, o desenvolvimento é impulsionado pela aprendizagem" (COLAÇO et al, 2007, p. 48).

Para fundamentar seu pensamento sobre incentivar a aprendizagem para se alcançar o desenvolvimento, Vigotski acredita na mediação de um adulto ou criança mais experiente para auxiliar nesta aprendizagem, pois somos seres sociais que aprendemos no convívio social, e "[...] o aprendizado humano pressupõe uma natureza social específica e um processo através do qual as crianças penetram na vida intelectual daqueles que as cercam" (VIGOTSKI, 2007, p. 100). Com isso, ele criou o termo Zona de Desenvolvimento Proximal, que consiste em dois pontos do caminho do desenvolvimento de um indivíduo: o nível de desenvolvimento real (aquilo que o indivíduo já possui como conhecimento) e o nível de desenvolvimento potencial (aquele conhecimento que está a ponto de ser adquirido, em processo de maturação); entre esses dois níveis encontra-se a Zona de Desenvolvimento Proximal, que nada mais é do que essa distância entre o nível real e o nível potencial de desenvolvimento.

Vigotski acredita que limitamos o indivíduo quando consideramos como conhecimento somente o que ele mostra conseguir realizar sozinho, sem o auxílio de uma pessoa mais experiente (o que denomina como nível de desenvolvimento real). Acredita que se deve explorar os conhecimentos que estão por vir (o nível de desenvolvimento potencial), os que o indivíduo pode realizar com o auxílio de instrumentos e signos por meio da mediação do educador ou colegas que já possuem esse conhecimento em nível real de desenvolvimento, sendo assim Vigotski (2007) diz que o

[...] nível de desenvolvimento real [...] define funções que já amadureceram, ou seja, os produtos finais do desenvolvimento. [...] A zona de desenvolvimento proximal define aquelas funções que ainda não amadureceram, mas que estão em processo de

\footnotetext{
5 "Vigotski viveu apenas 37 anos. Morreu de tuberculose em 1934. Apesar de breve, sua produção intelectual foi extremamente intensa e relevante: chegou a elaborar cerca de 200 estudos científicos sobre diferentes temas e sobre as controvérsias e discussões da psicologia contemporânea e das ciências humanas de um modo geral." (REGO, 2014, p.15)
} 
maturação, funções que amadurecerão, mas que estão presentemente em estado embrionário. Essas funções poderiam ser chamadas "brotos" ou "flores" do desenvolvimento, em vez de "frutos" do desenvolvimento. O nível de desenvolvimento real caracteriza o desenvolvimento mental retrospectivamente, enquanto a zona de desenvolvimento proximal caracteriza o desenvolvimento mental prospectivamente. $(2007$, p. 98$)$

Os professores, de acordo com essa perspectiva na leitura fruição, almejarão alcançar o nível de desenvolvimento potencial de seus alunos como (futuros) leitores, a ponto de despertar neles até mesmo o papel de futuros mediadores de seus colegas, ao compreenderem os conceitos empregados na prática de leitura pelo letramento literário ${ }^{6}$. É válido ressaltar neste ponto que "para trabalhar com crianças é imprescindível, antes, aprender sobre elas" (DAROS; PALUDO, 2013, p. 158).

Necessário se faz, portanto, considerar a importância que a linguagem (oral e escrita) tem em nossas vidas, já que as letras e números nos cercam por todas as partes: na rua, em nossas casas, objetos, roupas, produtos alimentícios, de higiene - isso para citar apenas alguns - conscientizando-nos de que "Signos e palavras constituem para as crianças, primeiro e acima de tudo, um meio de contato social com outras pessoas" (VIGOTSKI, 2007, p. 18).

Para melhor compreender a ligação entre a perspectiva histórico-cultural e a leitura fruição em sala de aula, é necessário um aprofundamento na teoria de Vigotski que até então foi introduzida de forma breve e sucinta. Passemos, pois, a contextualizar seu pensamento com o intuito de esclarecer sua reviravolta na Psicologia, contestando conceitos adotados em sua época, e entender o porquê embora tenham se passado anos, sua teoria é chamada de contemporânea.

A partir dos estudos desenvolvidos por Rego (2014), Lev Semenovitch Vigotski, nascido em 17 de novembro de 1896 em Orsha na Bielo-Rússia, viveu por um tempo em Gomel, onde até seus 15 anos de idade recebeu educação domiciliar com tutores particulares; desde muito cedo se mostrou ávido por conhecimento, buscando leituras sobre assuntos diversos não somente em textos russos, mas em outras línguas, como o alemão, latim, hebraico, francês e inglês. Viveu com seus sete irmãos em uma família de descendência judaica. Filho de um pai bancário e trabalhador de agência de seguros e uma mãe que dedicou parte de sua vida para criar seus filhos, embora formada como professora. Aos 28 anos de idade casou-se com Roza Smekhova e tiveram duas filhas. Veio a falecer em 11 de junho de 1934 aos 37 anos, em Moscou, após 14 anos convivendo com a tuberculose.

\footnotetext{
${ }^{6}$ Assunto que encontra melhor desenvolvimento no segundo momento deste artigo. 
Completou a educação básica em 1913 em uma escola privada de Gomel e, já em 1914, iniciou o estudo em Direito e Literatura, se formando em 1917 - com seus 21 anos - na Universidade de Moscou, dando início a sua carreira; no mesmo período frequentou os cursos de História e Filosofia na Universidade Popular de Shanyavskii, porém não recebeu nenhum certificado de conclusão, pois participava apenas como ouvinte. Seu interesse no psicológico humano e anomalias físicas e mentais levaram Vigotski a cursar medicina em Moscou e em Kharkov (REGO, 2014) ${ }^{7}$.

As teorias psicológicas adotadas na Rússia pós-revolucionária eram as comportamentais, que acreditam no estímulo-resposta, derivadas do pensamento behaviorista e darwiniano, que caracterizam o ser humano como um ser biológico, afastando a psicologia dos estudos, especificamente humanos, já que não acreditam no psíquico como parte do desenvolvimento (MACHADO; FACCI; BARROCO, 2011).

Para essa corrente de pensamento, a aprendizagem ocorria oferecendo às crianças estímulos para que alcançassem as respostas esperadas pelos adultos educadores. Portanto, eram direcionadas atividades estimuladoras de uma resposta que se buscava ter (VIGOTSKI, 2007, p. XVII $)^{8}$. Acreditavam que a aprendizagem só poderia ocorrer após o indivíduo alcançar certo nível de desenvolvimento, sendo assim, consideravam o desenvolvimento biológico, uma maturação do corpo e da mente, que caminham sozinhos, para somente depois poder se ensinar o que acreditavam ser adequado àquela etapa de maturidade.

Foi a partir daí que Vigotski iniciou uma "revolução" na psicologia de sua época, contestando tudo o que acreditavam sobre desenvolvimento e aprendizagem, dizendo, pois, que aprendizagem e desenvolvimento caminhavam separados até determinado ponto somente, pois se fundiam como uma única linha no final, porém nunca deixou de enfatizar que "[...] o desenvolvimento é sempre um conjunto maior que o aprendizado" (VIGOTSKI, 2007, p. 93), ou seja, que o desenvolvimento ocorre por meio do aprendizado, que é este - o aprendizado que impulsiona o primeiro - o desenvolvimento.

Entre as décadas 20 e 30 aconteceram os trabalhos mais relevantes de Vigotski na área educacional. Enfocava suas pesquisas no desenvolvimento e aprendizagem na Educação Infantil, não porque se preocupava especificamente com esta, mas porque acreditava que a

\footnotetext{
${ }^{7}$ Rego (2014) dedica o primeiro capítulo de seu livro a uma contextualização da vida de Vigotski, passando por informações da vida pessoal, profissional e do contexto social em que o autor viveu para justificar sua proposta de uma nova psicologia.

${ }^{8}$ Disponível na Introdução do livro "A formação social da mente”, em que caracterizam o contexto histórico e social em que Vigotski viveu na Rússia pós-revolucionária para melhor compreender seu pensamento e teorias.
} 
primeira infância caracterizava o desenvolvimento humano e, portanto, explicava o comportamento dos indivíduos no geral (REGO, 2014).

Vigotski deu início a muitos questionamentos em seus estudos, deixando alguns em processo de andamento, devido a sua interdisciplinaridade que o fez discorrer em meio a diversas áreas do conhecimento, e a seu falecimento precoce. Ainda assim, sua teoria muito contribui em estudos contemporâneos pelo seu caráter atual em nossas sociedades.

A perspectiva histórico-cultural, ou sociointeracionista de Vigotski, embora tenha sido desenvolvida há anos em uma sociedade de contexto muito diferenciado, pois acabava de sair de uma Revolução, encontra-se totalmente cabível nos dias atuais sem perder a sua veracidade e aplicabilidade. Decorrente disso é considerada contemporânea, motivo de estudos em cursos de nível superior na Psicologia e Pedagogia, usado como metodologia de instituições escolares, e como uma abordagem norteadora de práticas pedagógicas, acreditando na

Interação social entre as crianças como processos privilegiados de mediação
semiótica, isto porque, para os seres humanos, o desenvolvimento está
fundamentalmente governado não apenas por leis biológicas, senão por leis do
desenvolvimento cultural, implicadas nas transformações históricas e sociais
(COLAÇO et al, 2007, p. 49).

A perspectiva vigotskiana envolve, portanto, compreender que o desenvolvimento humano decorre da convivência dos indivíduos em sociedade, já que "[...] justifica o sociointeracionismo como desdobramento do materialismo histórico dialético posto que, a mediação cria as possibilidades de reelaboração (recriação) da realidade" (ZANOLLA, 2012, p. 8) e, portanto, o meio em que o indivíduo vive e os sujeitos com quem convive, personaliza-o, dando a ele características tipicamente humanas, mais especificamente, características típicas do ambiente e sujeitos com quem convive.

Entender a abordagem histórico-cultural como um norte na área educacional diz respeito a compreender as crianças como seres sociais que se desenvolvem cognitivamente no convívio social com indivíduos de sua cultura e sociedade. A partir disso, entendermo-nos como um ser diferente das outras espécies, como seres humanos, como um “[...] homem histórico-social e também biologicamente constituído, mas sobre o qual triunfaram as leis sociais e culturais" (MACHADO; FACCI; BARROCO, 2011, p. 656); homem este, que impulsiona os seus iguais ao desenvolvimento quando trazem atividades desafiadoras, saindo do estável para ampliar o repertório com novidades; novidades estas que só vamos conseguir realizar porque já se encontram em processo de maturação no nosso nível de desenvolvimento proximal. 
Vigotski revolucionou a Psicologia ao dizer que não precisamos esperar que ocorra o desenvolvimento biológico do corpo, atingindo muitas vezes fases - idades predeterminadas, para somente depois depararmo-nos com determinada aprendizagem, que teoricamente seríamos capazes de realizar por já termos desenvolvido as capacidades necessárias. Para Vigotski (2007), a aprendizagem leva os indivíduos ao desenvolvimento com atividades desafiadoras, pois;

[...] o aprendizado desperta vários processos internos de desenvolvimento, que são capazes de operar somente quando a criança interage com pessoas em seu ambiente e quando em cooperação com seus companheiros. Uma vez internalizados, esses processos tornam-se parte das aquisições do desenvolvimento independente da criança (2007, p. 103).

Não que Vigotski (2007) descartasse as questões biológicas do ser humano, ele apenas não atribuía a elas papel fundamental no despertar do desenvolvimento, afirmando que;

Podem-se distinguir, dentro de um processo geral de desenvolvimento, duas linhas qualitativamente diferentes de desenvolvimento, diferindo quanto à sua origem: de um lado, os processos elementares, que são de origem biológica; de outro, as funções psicológicas superiores, de origem socio-cultural. A história do comportamento da criança nasce do entrelaçamento dessas duas linhas (2007, p. 42).

Entendendo então, que o desenvolvimento das funções psicológicas superiores ocorre a partir de um ambiente de aprendizagem com outros indivíduos da sociedade em que se vive, Vigotski (2007) acrescentou à sua perspectiva histórico-cultural a teoria da

[...] zona de desenvolvimento proximal. Ela é a distância entre o nível de desenvolvimento real, que se costuma determinar através da solução independente de problemas, e o nível de desenvolvimento potencial, determinado através da solução de problemas sob a orientação de um adulto ou em colaboração com companheiros mais capazes (2007, p.97).

A teoria de Vigotski é muito usada no campo pedagógico, pois “[...] tornou-se conhecido como o homem que percebeu a determinação histórica da consciência e do intelecto humanos" (VIGOTSKI, 2008, p. VIII), e por isso, atribuiu-se à sua teoria um papel importante neste trabalho, pois se acredita que em um ambiente escolar "[...] o conceito de mediação leva à expectativa de uma relação de reciprocidade entre o indivíduo e as possibilidades do conhecer, aprender" (ZANOLLA, 2012, p. 6), já que todos os indivíduos envolvidos na aprendizagem são colaboradores de um desenvolvimento - ora um desenvolvimento próprio, ora um desenvolvimento para o próximo - tendo um contato pessoal com os objetos e conhecimentos do saber, atuando sobre eles e sendo possuinte destes. 
Pode-se notar então que, uma instituição escolar ou um professor que adota os princípios histórico-culturais em suas práticas pedagógicas, acredita em um aprendizado decorrente da troca mútua de conhecimento em situações em que tudo que se sabe vale para aprender e ensinar aos companheiros em sala (considerando tanto o professor quanto os alunos) e que o respeito mútuo dos sentimentos dos indivíduos que convivem, torna o ambiente propício a uma troca de aprendizagens que impulsione ao desenvolvimento, sendo necessário compreender que

\begin{abstract}
No cotidiano escolar, a intervenção "nas zonas de desenvolvimento proximal" dos alunos é de responsabilidade (ainda que não exclusiva) do professor visto como o parceiro privilegiado, justamente porque tem maior experiência, informações e a incumbência, entre outras funções, de tornar acessível ao aluno o patrimônio cultural já formulado pelos homens e, portanto, desafiar através do ensino os processos de aprendizagem e desenvolvimento infantil (REGO, 2014, p. 115)
\end{abstract}

Vigotski, em sua perspectiva histórico-cultural, abre-nos caminhos para compreender a sociedade em sua complexidade, pois se um indivíduo já traz consigo toda a complexidade do seu ser, uma sociedade carregada de indivíduos faz-se muito mais complexa de se entender. Por isso, em sua análise, o desenvolvimento ocorre de fora para dentro, ou seja, do social para o pessoal. Nas palavras de Vigotski (2007)

Um processo interpessoal é transformado num processo intrapessoal. Todas as funções no desenvolvimento da criança aparecem duas vezes: primeiro, no nível social, e, depois, no nível individual; primeiro entre pessoas (interpsicológica), e, depois, no interior da criança (intrapsicológica). [...] Todas as funções superiores originam-se das relações reais entre indivíduos humanos (p. 58).

É possível concluir, sem rodeio, com Vigotski (2007), que as relações reais entre indivíduos humanos têm seu nascedouro nas funções superiores e, por isto, a necessidade da interação com o outro em se tratando de relações sociais. Passa-se a discutir a questão da leitura fruição no contexto do letramento literário.

\title{
LEITURA FRUIÇÃO - LETRAMENTO LITERÁRIO
}

Retoma-se o conceito de leitura fruição entendendo como a leitura realizada pelo gozo em ler, sem a necessidade de haver uma atividade conseguinte da leitura, apenas a prática desta como uma atividade prazerosa em sala de aula com os alunos. Assim, Geraldi (2006) diz que:

Com "leitura - fruição de texto" estou pretendendo recuperar de nossa experiência uma forma de interlocução praticamente ausente das aulas [...]: o ler por ler, gratuitamente. E o gratuitamente aqui não quer dizer que tal leitura não tenha um resultado. O que define esse tipo de interlocução é o "desinteresse" pelo controle de resultado (p.98). 
Acredita-se que independente da especificidade do perfil de cada instituição escolar, todas devem preocupar-se com a apropriação de signos e instrumentos culturais das crianças, e a prática de leitura é um instrumento de apropriação cultural importante, considerando que "O âmbito escolar apresenta-se como fórum privilegiado para a apropriação da cultura, e o professor, como singular agente mediador deste processo" (SILVA; ALMEIDA; FERREIRA, 2011, p. 222) no trabalho pedagógico.

O professor "Tendo em vista que o espaço escolar é um lugar privilegiado de reflexão sobre a língua escrita, as rodas diárias de leitura literária podem permitir um enlace entre fruição estética e análise dos textos em diferentes perspectivas” (BOLOGNESI, 2012, p. 94), partirá, pois, deste princípio para interferir na vida de seus alunos apresentando-lhes o mundo da leitura e fazendo-lhes criar gosto por esta.

Entende-se e dá-se importância ao ambiente escolar e ao papel do professor em sala de aula, pois se percebe que se trata de um ambiente propício para disseminar conhecimentos, e o professor, peça fundamental deste jogo sócio-cultural, como mediador desse processo de aprendizagem, já que intencionalmente em seu trabalho, atua com instrumentos e signos culturais na zona de desenvolvimento proximal de seus alunos, para que possam alcançar a maturação de conhecimentos e atividades que sozinhos demorariam a alcançar, e que assim, elevem seus conhecimentos do interpsicológico ao intrapsicológico, ou seja, que o que aprendem no convívio social, possa ser internalizado. "Neste sentido, o outro é signo mediador de condutas, gestos, sentimentos e pensamentos, valendo lembrar que toda e qualquer função psicológica superior foi social antes de tornar-se interna ao indivíduo" (SILVA; ALMEIDA; FERREIRA, 2011, p. 222).

Colocando a leitura fruição dentro desta perspectiva, atribui-se à intencionalidade do trabalho pedagógico a importância de tornar os alunos da Educação Infantil, futuros leitores a partir da prática de ouvinte de leituras literárias realizadas em sala de aula pelo professor, que tem a prerrogativa de formar cidadãos aptos a conviverem em uma sociedade carregada de signos e instrumentos, dentre esses, o que aparece fortemente é a escrita alfabética. Porém, mais do que alfabetizar o aluno, os educadores precisam comprometer-se a letrá-lo, que diz respeito a torná-los "versado em letras; erudito" (FERREIRA. 2001, p. 424), ou seja, é mais do que ensinar a grafia e decifração das representações alfabéticas, é a aptidão de compreender a significância do que se lê, não somente ler os signos alfabéticos construídos socialmente sem atribuir-lhes significado, caracterizando uma leitura sem fundamento e relevância para o leitor. 
Vê-se como característica de um professor preocupado com este compromisso, a busca por gêneros textuais diferentes para apresentar aos seus alunos: fábulas, lendas, contos, piadas, biografias, notícias, textos explicativos, receitas, entre tantos outros. Dentro desses vários gêneros, o compromisso ainda em apresentar e caracterizar aos alunos ouvintes, o livro ou texto que será lido: nome do autor, nome do ilustrador, nome da editora, a ilustração e título do texto; todas essas informações apresentadas em um componente de muita importância: a capa, justamente "[...] por ser a capa a porta de entrada do texto para o leitor" (RAMOS; NUNES, 2013, p. 254), mostrando-lhes e fazendo-lhes questionar-se sobre o que o texto vai lhes contar.

Atribui-se à leitura uma grande importância na vida dos cidadãos, acreditando, pois, que pode tardar, mas o mundo da leitura alcança a todos, e "[...] a literatura é um conhecimento indispensável aos seres humanos, ao fornecer a possibilidade de viver dialeticamente problemas, além de ordenar nossa mente e sentimentos" (RAMOS; NUNES, 2013, p. 253), e que quanto mais familiarizado o indivíduo estiver com este signo cultural, mais prazerosa lhe será a leitura. Parte daí o princípio de atribuir à Educação Infantil essa prática, para que desde pequenos os indivíduos sejam apresentados à leitura e que aprendam assim, sua importância, gostos e delícias de ler.

O educador pode explorar os componentes da leitura, apresentando diariamente a cada livro ou texto que lê aos seus pequenos alunos ouvintes, compreendendo que o livro não se faz apenas com o texto escrito em seu interior, mas pela sua capa e informações que traz, e sua ilustração, que muito nos conta dos textos, sendo possível até mesmo, explorar a história sem a leitura das grafias, já que "A fresta aberta pela imagem, neste caso a ilustração, tornase, portanto, uma brecha para viver experiências sensoriais, imaginativas, desafiadoras, estéticas e de total fruição" (RAMOS; NUNES, 2013, p. 255).

Quando se trata de livros infantis, uma característica marcante é a ilustração, "E essa oportunidade de interagir com a narrativa por meio da ilustração confere a esse tipo de imagem o seu valor artístico e permite ao leitor vivenciar uma experiência de leitura estética condizente com o texto literário ao qual essa imagem ilustra" (RAMOS; NUNES, 2013, p. 262). Por isso faz-se necessário a apresentação desse corpo tão importante e presente nos livros (principalmente infantis): o ilustrador. A partir do ilustrador é que acontece a magia da ilustração que nos conta a história por imagens e cores que representam o texto escrito, e mais, podendo nos levar além do que o texto escrito em si já nos diz: 


\begin{abstract}
A ilustração atrai o olhar do sujeito que se deslumbra e se volta sobre o que vê, para interagir com o texto, ou seja, com a nova realidade apresentada pela imagem. Em síntese, a ilustração convida o leitor a viver uma experiência estética, não se trata apenas de observar uma obra artisticamente executada, percebendo seus materiais ou técnicas de produção, mas de recebê-la, percebê-la, senti-la, deixar-se levar pela emoção que aquele conjunto, artisticamente constituído, provoca (RAMOS; NUNES, 2013, p. 254-255).
\end{abstract}

Acredita-se que uma boa ilustração diz mais do que as próprias palavras do texto, esta pode nos levar a enxergar além do que interpretamos no momento da leitura, “[...] permitindo ao leitor enxergar o verbal a partir de uma outra ótica e criar novas imagens a partir da interação com o que vê/lê" (RAMOS; NUNES, 2013, p. 255), por isso a importância de mostrar aos alunos cada página do livro a medida que se lê, para que ele possa conhecer todos os componentes do texto, criar e imaginar a história a partir de sua experiência auditiva e visual.

A leitura da ilustração é tão importante, que seu uso tem sido muito explorado pelos escritores de histórias infantis, que têm criado ultimamente, livros e coleções de histórias sem texto escrito ${ }^{9}$. Esse tipo de texto, além de poder ser trabalhado em roda de leitura literária pelo professor, faz do aluno ouvinte, agora autor de sua própria leitura, convidando-o a ler sozinho e interpretar a ilustração para realizar a leitura de sua história, pois entende-se que "[...] o conteúdo da imagem dá ao leitor uma visão a respeito da ação narrativa, permitindo que esse sujeito, por meio de leitura, construa um sentido para o que vê/lê" (RAMOS; NUNES, 2013, p. 261).

Não se pode esquecer de uma outra importante característica da leitura literária infantil: a personificação dos personagens e sentimentos dos mesmos por meio da voz do professor leitor. A leitura fruição é aqui entendida como "[...] um processo de interlocução entre leitor/autor mediado pelo texto" (GERALDI, 2006, p. 91). Assim como o professor medeia a relação de seus alunos com o objeto livro, o texto é o mediador da relação leitor (no caso o professor) e a sua interlocução. Com isso entendemos que o texto nos diz muito mais do que a história que conta, e com personificação queremos dizer sobre a importância da entonação de voz dada pelo professor na hora da leitura, para caracterizar o texto personagens: menino (a), avô (ó); sentimentos/estado: bravo (a), feliz, triste, chorando, doente; onomatopeias: "atchim", "pow”, “nhac", "boom” - "É por isso que se pode falar em

\footnotetext{
9 Vale como sugestão os livros "O jornal" e "O lenço" de Patrícia Auerbach. Livros sem texto escrito, todo ilustrativo e convidativo à imaginação infantil ao interpretar as ilustrações.
} 
leituras possíveis e é por isso também que se pode falar em leitor maduro" (GERALDI, 2006, p. 91).

Passa-se a pensar nesta prática de leitura em sala de aula em busca da qualidade da leitura dos alunos, considerando o que Geraldi (2006, p. 99) diz que "[...] a qualidade (profundidade?) do mergulho de um leitor num texto depende - e muito - de seus mergulhos anteriores. A quantidade ainda pode gerar qualidade. Parece-me que deveremos - enquanto professores - propiciar um maior número de leituras" e preocuparmo-nos com o modo com que interfere na vida e formação social dos alunos da Educação Infantil de modo a incentiválos como futuros leitores a partir de suas primeiras experiências, por ora como ouvinte.

A educação escolar é um direito de crianças e de adolescentes, inclusive adultos que não tiveram acesso na idade apropriada, assegurado na Constituição da República Federativa do Brasil (1988), no artigo 207, parágrafo segundo, inciso primeiro, na emenda constitucional número 59 do ano de 2009, explicitando que a "educação básica obrigatória e gratuita dos 4 (quatro) aos 17 (dezessete) anos de idade, assegurada inclusive sua oferta gratuita para todos os que a ela não tiveram acesso na idade própria”. O ambiente escolar tem, pois, por obrigação; a formação de cidadãos críticos, conscientes e participantes ativos da sociedade em que vivem desde a infância até a fase adulta se for necessário.

Acreditando nisso é que se desperta o olhar à prática de leitura diária, atribuindo a ela a devida importância, partindo do princípio de que somos parte de uma sociedade que aprendeu a se comunicar graficamente com a escrita alfabética, e que para estarmos e fazermos parte desta sociedade, precisamos nos familiarizar com este signo cultural tão presente em nosso cotidiano.

Se aposta no letramento para dar significado ao que lemos, para que esse signo social conhecido como escrita alfabética, passe a ter um sentido mais profundo e possa ser interpretado e interiorizado no momento da leitura, não apenas lido sem assimilação e entendimento $^{10}$. “Atuando neste 'espaço', o professor tem a possibilidade de potencializar os modos mais adequados ao desenvolvimento real do indivíduo e ao seu contexto sociocultural" (SILVA; ALMEIDA; FERREIRA, 2011, p. 221), e é, pois, acreditando nisso, que se vê a leitura fruição como um rico momento de apropriação de sentidos dos signos culturais.

\footnotetext{
${ }^{10}$ Muito tem se discutido atualmente sobre a diferenciação entre alfabetização e letramento para a formação de cidadãos realmente alfabetizados. Usa-se o termo "analfabeto funcional" para o indivíduo que embora consiga ler e escrever textos, possui dificuldade de compreensão na leitura, precisando às vezes, retomar a leitura uma ou mais vezes para procurar entender o que lê.
} 
As crianças são seres sociais que estão em um momento de descoberta da vida, explorando o que não conhecem, e conhecendo por meio dos adultos mediadores que lhes apresentam os instrumentos e signos de nossa sociedade, "Na escola esse mediador é, fundamentalmente, o professor" (GOMES, 2013, p. 517). Acredita-se, pois, que para ocorrer uma mediação significativa, que realmente interfira na vida do aluno, é primoroso pensar que a:

[...] motivação para a aprendizagem implica pensar em afetação, em como a criança se encontra com os objetos do conhecimento, como se dá essa relação perpassada por ideias, objetos e fenômenos da realidade escolar, ou seja, como são os elementos mediadores que participam do processo de conhecimento (GOMES, 2013, p. 517).

Confessa-se uma visão um tanto quanto romantizada acreditando no potencial da profissão docente em mudar a sociedade, tornando-a melhor, começando ao "Recuperar na escola e trazer para dentro dela o que dela se exclui por princípio - o prazer - me parece o ponto básico para o sucesso de qualquer esforço honesto de "incentivo à leitura'" (GERALDI, 2006, p. 98), pois é preciso pensar no professor mediador como um ser social também, carregado de bagagem de suas interações sociais e marcado por elas, já que,

[...] é por meio das interações tecidas ao longo de sua história de vida que alguém se torna professor, e é nas e pelas interações que ele conhece, experimenta e organiza sua prática, as filigranas que configuram suas relações com o aluno e outros aspectos que constituem a aula propriamente dita, a sala de aula e a escola, considerando-se também a educação de modo geral (SILVA; ALMEIDA; FERREIRA, 2011, p. 223).

Pensa-se em compreender a complexidade que há nas relações sociais tecidas no ambiente escolar, concebendo que o professor, que é o mediador neste espaço social, também já foi e ainda é mediado em outros espaços sociais, ou seja, assim como marca a vida de seus alunos com suas interferências, também carrega suas marcas de interferências vividas. Pensando assim talvez torne-se motivador para um professor planejar sua prática pedagógica, de modo a procurar meios de melhor interferir e marcar a vida de seus alunos como cidadãos procurando na prática de leitura fruição - o foco deste trabalho - " [...] uma interlocução honesta com seus possíveis leitores. E honesta, aqui, não tem um sentido moralista. Honesta porque só se concretizará com o outro-leitor que o complementará por sua palavra" (GERALDI, 2006, p. 99).

Concerne ao professor atentar-se às especificidades de cada aluno para sensibilizar-se de que, por mais que a leitura fruição seja feita em um momento coletivo, cada aluno possui sua cadência para se familiarizar, se apropriar e dominar determinado conhecimento apresentado e "O respeito pelos passos e pela caminhada do aluno enquanto leitor (que se faz 
pelas suas leituras, como nos fazemos leitores por nossas leituras) é essencial. Nessa caminhada é importante considerar que o enredo enreda o leitor” (GERALDI, 2006, p. 98), portanto, sua caminhada e seu ritmo são deveras importantes para seu desenvolvimento enquanto cidadão. Neste campo, é sempre importante ressaltar que:

\begin{abstract}
As particularidades das vivências de cada criança são a base da diversificação para suas interpretações e significações. Porém, essas interpretações e significações estão fortemente relacionadas aos modos como a mediação do adulto é realizada, tecendose, nas interações, a complexa rede pelas quais ambos - criança e adulto - se relacionam com os atos de leitura e com os livros em si. (BRITO; ROCHA, 2016, p. 61)
\end{abstract}

Passa-se à discussão da práxis educativa na perspectiva histórico-cultural.

\title{
A PRÁXIS EDUCATIVA NA PERSPECTIVA HISTÓRICO-CULTURAL
}

Faz-se necessário analisar neste terceiro e último momento do artigo sobre a práxis educativa, ou seja, tematizar ainda que teoricamente, como se daria a prática do professor em sala de aula, incorporando essa corrente à prática de leitura trabalhada aqui até então.

Em que pese o fato de que "[...] embora o aprendizado da criança se inicie muito antes de ela frequentar a escola, o aprendizado escolar introduz elementos novos no seu desenvolvimento" (REGO, 2014, p. 72), ou seja, sabe-se que o desenvolvimento humano se dá muito antes de sua ativa presença e participação no ambiente escolar. Porém, a educação escolar favorece o desenvolvimento do indivíduo nas questões acadêmicas de âmbito disciplinar/curricular, e em questões sociais de interações com semelhantes de sua cultura, havendo uma vivência rica e concreta.

Entende-se, pois, que o professor, principal mediador no ambiente escolar, preocupado em apresentar a seus alunos além dos conceitos escolares existentes nas grades curriculares, que pretendem um padrão de escolarização já na Educação Infantil; preocupar-se-á em elaborar aulas que semeiem conceitos históricos e culturais na vida de seus alunos, já que “[...] a escola, por oferecer conteúdos e desenvolver modalidades de pensamento bastante específicos, tem um papel diferente e insubstituível, na apropriação pelo sujeito da experiência culturalmente acumulada" (REGO, 2014, p. 103), cabendo a escola e ao professor então, formar o cidadão crítico e ativo em conhecimentos específicos e culturais da história da humanidade.

Considerando que "[...] a necessidade humana de contar histórias é uma característica prosaica” (BELMIRO, 2012, p. 111), e ainda que a comunicação oral e escrita são signos importantes de nossa sociedade, elaborou-se essa pesquisa com o interesse em enraizar a 
leitura como fruição no cotidiano da Educação Infantil, para que futuramente o objeto livro e a prática de leitura, não sejam elementos estranhos às crianças e jovens em uma sociedade carregada por esses signos e instrumentos culturais. Com isso, concebe-se que "[...] o bom ensino é aquele que se adianta ao desenvolvimento, ou seja, que se dirige às funções psicológicas que estão em vias de se completarem" (REGO, 2014, p. 107), planejando um ensino que não alcance só o imediato, mas que preveja as situações futuras dos seres sociais, dos discentes que passarão na vida de cada professor.

A perspectiva histórico-cultural de Lev Semenovitch Vigotski, por abranger diversos contextos das relações sociais dos indivíduos, tem grande alcance também em variadas áreas de estudos; o próprio Vigotski elaborou aproximadamente 200 estudos científicos nas mais distintas áreas do conhecimento dentro da psicologia contemporânea e das ciências humanas (REGO, 2014). Com isso, queremos ressaltar que falar sobre sua perspectiva de modo geral é deveras abrangente, e esta pesquisa compromete-se a especificar a discussão neste momento à prática pedagógica do docente em sala com o intuito de incentivar à leitura.

Essa perspectiva encontra-se presente na epistemologia pedagógica de muitas instituições escolares da atualidade. Levando o nome também de perspectiva sociointeracionista ou sociocultural, essa perspectiva adotada em âmbito escolar caracteriza a mesma como uma instituição que tem como princípio a mediação e interação entre os seres sociais para melhor apropriação e desenvolvimento dos conhecimentos, ou seja, uma instituição escolar que compreende que;

[...] o desenvolvimento do sujeito humano se dá a partir das constantes interações com o meio social em que vive, já que as formas psicológicas mais sofisticadas emergem da vida social. [...] Por intermédio dessas mediações, os membros imaturos da espécie humana vão pouco a pouco se apropriando dos modos de funcionamento psicológico, do comportamento e da cultura, enfim, do patrimônio da história da humanidade e de seu grupo cultural. Quando internalizados, estes processos começam a ocorrer sem a intermediação de outras pessoas (REGO, 2014, p. 60).

Compreende-se, portanto, a partir dessa perspectiva, que a escola é o ambiente social propício para a disseminação de conhecimentos acumulados historicamente pelos grupos sociais antecedentes, e vendo-a além deste ponto, concebendo-a como um local propício para o convívio com seres semelhantes, "Essa forma de relação torna-se possível somente graças à experiência alheia ou experiência social" (VIGOTSKI, 2009, p. 24) em que um indivíduo auxilia no desenvolvimento do outro buscando a maturação de conhecimentos que estão em níveis de desenvolvimento real ou proximal. 
Pensa-se que raramente algumas características culturais farão parte do cotidiano de um indivíduo sem que tenha havido uma apresentação e incentivo de determinado conceito. Raramente uma criança da Educação Infantil deparar-se-á com um livro e o abrirá folheandoo buscando compreender uma história, sem nunca antes ter sido apresentado este conceito de que um livro se abre, se folheia e nas ilustrações e escritas (signos de nossa sociedade) encontram-se histórias a serem contadas. Dir-se-á ainda que, raramente uma criança já no Ensino Fundamental, entrará por vontade própria em uma livraria ou biblioteca buscando livros que o interessem se em seu cotidiano não houver um incentivo pela prática de leitura ainda que falte este incentivo na escola, provavelmente encontrar-se-á em outras relações sociais, como a familiar, por exemplo.

A partir dessa reflexão pensa-se ser importante o incentivo dessa prática que enriquece a vida dos indivíduos, e se considera importante, por que não incentivar desde cedo na Educação Infantil? A criança na Educação Infantil não conseguirá ler a escrita convencional, mas poderá criar gosto pela leitura ao ouvir as histórias contadas pelos livros, e ao interessarse pelo objeto livro, possivelmente começará a construir suas leituras "[...] caracterizado pela presença da ilustração associada à palavra" (RAMOS; NUNES, 2013, p. 251) tornando-se possivelmente um leitor ávido num futuro próximo.

Elaborar propostas pedagógicas fundamentadas na perspectiva histórico-cultural corresponde a pensar em uma educação que vai adiante nos ensinamentos. Com isso, se quer dizer sobre uma educação que trace caminhos futuros aos alunos, e não uma educação que fique estacionada no que o aluno já possui e consegue realizar sozinho de forma satisfatória. "O esforço em desempenhar com fidelidade aquilo que observa em sua realidade faz com que ela atue num nível bastante superior ao que na verdade se encontra" (REGO, 2014, p. 82), e é essa a base do pensamento de um professor que procura instigar novos conhecimentos e aprendizagens na vida de seus alunos, tirando-os de sua zona de conforto, apresentando-lhes sempre mais novidades.

Um professor não pode ter a ilusão de que apresentar novos conhecimentos que desafiem os limites da zona de desenvolvimento real de seus alunos seja uma tarefa fácil e nem que vá ocorrer de forma igualitária para todos os alunos da turma, "Para aprender um conceito é necessário, além das informações recebidas do exterior, uma intensa atividade mental por parte da criança" (REGO, 2014, p. 78), e isso corresponde a compreender que cada indivíduo se desenvolve em seu tempo, à sua maneira, que cada um possui suas facilidades e dificuldades. 
Essa intencionalidade do professor em promover o gosto pela leitura por meio da prática de leitura fruição diária, marca a vida das crianças na Educação Infantil, assim como "[...] ocorre com a marca deixada pela roda na terra fofa: forma-se uma trilha que fixa as modificações produzidas pela roda, facilitando o seu deslocamento no futuro. De modo semelhante, em nosso cérebro, estímulos fortes ou que se repetem com frequência abrem novas trilhas" (VIGOTSKI, 2009, p. 13). Pensa-se que seja este o desafio e a meta do professor - aqui no caso, de Educação Infantil -, elevar os conhecimentos de seus alunos da melhor maneira possível para uma vida em sociedade.

O ensino que é apresentado mostrando significativa importância na vida dos alunos, os conquistam com maior facilidade, por isso "Um de nossos desafios seria pensar quais são os motivos sociais da atividade estudo em nossa sociedade" (ASBAHR, 2014, p. 271), para que assim, o ensino ocorra de forma prazerosa ao ser "abraçado" pelos alunos.

Mais uma vez ressalta-se a importância que o ambiente escolar possui na formação social e cultural dos indivíduos, uma vez que mais do que um grupo social em que se estabelecem relações, a escola é também um ambiente de aprendizado intencional mediado pelo professor, que nessa perspectiva histórico-cultural, entende “[...] que o ser humano se constitui nas e pelas relações que estabelece com o mundo físico e social, tendo em vista atender às suas necessidades, isto é, constitui-se por sua atividade" (MARTINS; EIDT, 2010, p. 676), e com isso, elabora propostas pedagógicas que visam em sua prática docente um semear de conhecimentos necessários para vida social de um cidadão ativo.

Considerando que nossa sociedade, desde os primórdios, se comunica, além da linguagem oral, por meio de representações escritas ou pictóricas, a alfabetização e letramento tomam lugar central nos ensinamentos escolares, principalmente nos anos iniciais de escolarização. Na Educação Infantil, a alfabetização não está estritamente presente, porém a preocupação pelo letramento está cada vez mais enraizada na educação contemporânea. É pensando na importância social que a escrita e leitura possuem e, na prática de letramento, que busca formar cidadãos alfabetizados integralmente, que este trabalho se estrutura com a leitura fruição como prática diária na Educação Infantil.

As crianças da Educação Infantil, ainda muito pequenas, procuram motivações específicas de sentimentos entre gostar ou não gostar de determinada atividade, momento ou proposta do professor. Por isso, o momento de leitura fruição precisa ter um propósito que atenda às necessidades das crianças, pois "[...] a ocorrência da aprendizagem depende do sentido que esta tenha para o sujeito, o que requer que o professor estruture a atividade de Momento: diálogos em educação, E-ISSN 2316-3100, v. 26, n. 1, p. 74-95, jan./jun. 2017 
estudo de modo que os objetos a serem aprendidos tenham lugar estrutural na atividade dos estudantes" (ASBAHR, 2014, p. 271) e, além disso, configurar-se como um momento prazeroso para que as crianças anseiem esta ocasião diária no cotidiano e que busquem essa prática por motivos pessoais.

O professor incumbir-se-á de modificações sociais e pessoais na vida de todos os discentes que cruzarão sua vida, e se responsabilizará pela apropriação de conhecimentos que os mesmos terão, e "A apropriação da cultura acontece de forma transformadora: o homem transforma as atividades externas ao seu organismo e as interações com o outro em atividades internas e intrapsicológicas" (SILVA; ALMEIDA; FERREIRA, 2011, p. 221); tudo isso acontecerá aos olhos do professor, de forma mais intensa ou menos intensa, mas acontecerá a todos os seus alunos, em todos os anos de trabalho. E não há nada mais recompensador do que sentir-se parte do crescimento de indivíduos que tornar-se-ão ativos na sociedade em que vivem.

\section{CONSIDERAÇÕES FINAIS}

A pergunta que fundamentou o caminhar dessa pesquisa - de que maneira a prática do professor em sala pode despertar o conhecimento e interesse da criança pela leitura? - foi devidamente respondida de acordo com o que se esperava, considerando que a resposta previamente pensada foi de que, o modo com que o professor se relaciona com o livro em sala de aula interfere no modo com que as crianças relacionar-se-ão com os mesmos, já que dentro do ambiente escolar a figura de maior representatividade, principalmente na Educação Infantil, é o professor.

Quando se pensa a Educação Infantil, pensa-se a respeito de crianças pequenas até seus cinco anos de idade. É um momento crucial de formação de diversos conceitos que se explorarão com maior intensidade nos anos escolares seguintes, porém é nesta etapa que se inicia, e sendo assim, é impossível ignorar a necessidade dessa exploração inicial. Pensa-se, pois, em uma criança que já na Educação Infantil adentrou no mundo da leitura, conheceu e se familiarizou com o objeto livro e suas características, e aprendeu a respeitar e apreciar o momento de leitura tanto realizado por outra pessoa, como por ela mesma, ainda que sem compreender a escrita alfabética. Após realizarmos essa pesquisa, confirmou-se a ideia prévia de que a criança que na Educação Infantil sofrer estímulos de leitura que façam desenvolver nela essa "semente" em fase embrionária; maturará um conhecimento que a acompanhará em toda sua vida, que a fará participar mais ativamente de uma sociedade marcada por este signo e poderá se tornar um leitor assíduo. 
Com essa prática pedagógica que intenciona o desenvolvimento de um futuro leitor, procura-se também combater o que atualmente tanto se discute na educação: o analfabetismo funcional. Trata-se das pessoas que foram alfabetizadas, conhecem e sabem ler e escrever, mas não conseguem compreender com nenhuma ou pouca facilidade o que leem. Considerase que quando se aposta na prática de leitura fruição na Educação Infantil como um incentivador de futuras leituras assíduas, se aposta também na prática de letramento, que vai além da alfabetização, visando formar cidadãos leitores seguros e preparados para uma vida ativa em sociedade.

A leitura fruição foi tratada neste trabalho de modo a planejar a construção de uma cultura característica de nossa sociedade grafocêntrica no momento presente para uma educação futura. E com isso, se quer dizer que quando a leitura é explorada ludicamente como um momento prazeroso para as crianças da Educação Infantil, poder-se-á a partir da leitura deleite, incentivar o gosto pelo mundo da leitura ainda enquanto crianças pequenas para que se sintam parte desse conhecimento cultural e façam parte do mesmo, não apenas inseridos, mas pertencentes e participantes desta cultura.

Portanto, é fundamental que sejam pensadas formas de favorecer e intensificar a leitura fruição como estratégia para o desenvolvimento da habilidade de leitura de estudantes da Educação Infantil, em um primeiro momento, mas, sobretudo, que se crie alternativas para que os professores possam ultrapassar a dimensão da leitura como obrigação, embora esta obrigação tenha a sua necessidade, para um além da obrigação, para o deleite, para o prazer da própria leitura.

\section{REFERÊNCIAS}

ASBAHR, F. da S. F. Sentido pessoal, significado social e atividade de estudo: uma revisão teórica. Psicol. Esc. Educ. [online]. 2014, vol.18, n.2, p. 265-272. Disponível em: $<$ http://www.scielo.br/pdf/pee/v18n2/1413-8557-pee-18-02-0265.pdf $>$ Acesso em: 11 nov. 2014.

BELMIRO, C. A. Entre modos de ver e modos de ler, o dizer. Educ. rev. [online]. 2012, vol.28, n.4, p. 105-131. Disponível em: <http://www.scielo.br/pdf/edur/v28n4/05.pdf > Acesso em: 08 nov. 2014.

BOLOGNESI, P. M. S. Rodas de leitura na escola: do envolvimento dos alunos aos processos de reflexão. 2012. 156 fl. Dissertação (Mestrado em Educação) - Faculdade de Educação, Universidade de São Paulo, São Paulo, 2012. Disponível em: $<$ http://www.teses.usp.br/teses/disponiveis/48/48134/tde-05062012-115930/> Acesso em: 19 abr. 2015.

BRASIL. Constituição 1988. Constituição da República Federativa do Brasil. Brasília, DF, Senado, 1998. 
BRITO, L. E. B.; ROCHA, M. S. P. M. L. da. Literatura na Educação Infantil: modos de trabalho com textos e possibilidades do desenvolvimento da capacidade criativa. Leitura: Teoria \& Prática, Campinas, São Paulo, v.34, n.68, p.45-64, 2016.

COLAÇO, V. de F. R. et al. Estratégias de mediação em situação de interação entre crianças em sala de aula. Estud. psicol. (Natal) [online]. 2007, vol.12, n.1, p. 47-56. Disponível em: $<$ http://www.scielo.br/pdf/epsic/v12n1/a06v12n1.pdf> Acesso em: 08 nov. 2014.

CORDÃO, T. S. R.; AZEVEDO, H. H. O. (orientadora). Necessidades formativas de professores de crianças de zero a três anos de idade. 2013. 202 fl. Dissertação (Mestrado) - Pontifícia Universidade Católica de Campinas, Centro de Ciências Aplicadas, PósGraduação em Educação.

DAROS, T. M. V.; PALUDO, K. I. Qual criança? Qual infância? Qual qualidade na educação infantil? Rev. Educ. PUC-Camp., Campinas, 18(2):151-159, maio/ago., 2013

FERREIRA, Aurélio Buarque de Holanda; ANJOS, Margarida dos; FERREIRA, Marina Baird. Aurélio Século XXI: o dicionário da língua portuguesa / Aurélio Buarque de Holanda Ferreira; coordenação e edição Margarida dos Anjos, Marina Baird Ferreira. 3.ed. Rio de Janeiro, RJ: Nova Fronteira, 2001.

GERALDI, J. W. Prática da leitura na escola. In: GERALDI, J. W. (Org.). O texto na sala de aula. 4.ed. São Paulo: Ática, 2006.

GOMES, C. A. V.O lugar do afetivo no desenvolvimento da criança: implicações educacionais. Psicol. estud. [online]. 2013, vol.18, n.3, p. 509-518. Disponível em: $<$ http://www.scielo.br/pdf/pe/v18n3/v18n3a11.pdf> Acesso em 11 nov. 2014.

MACHADO, L. V.; FACCI, M. G. D.; BARROCO, S. M. S. Teoria das emoções em Vigotski. Psicol. estud. [online]. 2011, vol.16, n.4, p. 647-657. Disponível em: $<$ http://www.scielo.br/pdf/pe/v16n4/a15v16n4.pdf> Acesso em: 11 nov. 2014.

MARTINS, L. M.; EIDT, N. M. Trabalho e atividade: categorias de análise na psicologia histórico-cultural do desenvolvimento. Psicol. estud. [online]. 2010, vol.15, n.4, p. 675-683. Disponível em: <http://www.scielo.br/pdf/pe/v15n4/v15n4a02.pdf> Acesso em: 11 nov. 2014.

RAMOS, F. B.; NUNES, M. F. Efeitos da ilustração do livro de literatura infantil no processo de leitura. Educ. rev. [online]. 2013, n.48, p. 251-263. Disponível em: $<$ http://www.scielo.br/pdf/er/n48/n48a15.pdf> Acesso em: 08 nov. 2014.

REGO, C. T. Vigotsky: Uma perspectiva histórico-cultural da educação. 25 ed. Petrópolis, RJ: Editora Vozes Ltda, 2014.

SILVA, S. M. C. da; ALMEIDA, C. M. de C.; FERREIRA, S. Apropriação cultural e mediação pedagógica: contribuições de Vigotski na discussão do tema. Psicol. estud. [online]. 2011, vol.16, n.2, p. 219-228. Disponível em: $<$ http://www.scielo.br/pdf/pe/v16n2/a05v16n2.pdf> Acesso em: 14 nov. 2014.

SMOLKA, A. L. Apresentação e comentários. VIGOTSKI, L. S. (Lev Semenovich). Imaginação e criação na infância: ensaio psicológico: livro para professores / Lev Semionovich Vigotski; apresentação e comentários Ana Luiza Smolka; tradução Zoia Prestes - São Paulo: Ática, 2009. 
VIGOTSKI, L. S. (Lev Semenovich); COLE, Michael (Orgs.). A formação social da mente: o desenvolvimento dos processos psicológicos superiores. 7.ed. São Paulo, SP: Martins Fontes, 2007. 182 p.

Imaginação e criação na infância: ensaio psicológico: livro para professores / Lev Semionovich Vigotski; apresentação e comentários Ana Luiza Smolka; tradução Zoia Prestes - São Paulo: Ática, 2009.

Pensamento e linguagem. São Paulo, SP: Martins Fontes, 1993. Xviii, 135 p.

ZANOLLA, S. R. S. O conceito de mediação em Vigotski e Adorno. Psicol. Soc., Abr 2012, vol.24, no.1, p.5-14. Disponível em: <http://www.scielo.br/pdf/psoc/v24n1/02.pdf> Acesso em: 08 nov. 2014. 